\title{
Democracy and resilient pro-social behavioral change: an experimental study
}

\author{
Kenju Kamei ${ }^{1}$
}

Received: 28 December 2015 / Accepted: 5 May 2016 / Published online: 26 May 2016 (C) The Author(s) 2016. This article is published with open access at Springerlink.com

\begin{abstract}
Both experimental and empirical studies have shown that democratically imposing a policy that encourages cooperation may increase its effectiveness by enhancing the voters' cooperation behavior. But, do those involved in the democratic decision-making process change their behavior when faced with an exogenously implemented rule? This paper experimentally shows that the voters that are involved in a successful democratic selection of a policy behave more pro-socially as consistent with recent studies. My experiment moreover shows that such a successful democratic imposition of the policy may increase the voters' level of cooperation even when the policy is undemocratically imposed.
\end{abstract}

\begin{abstract}
I am grateful to Pedro Dal Bó for invaluable guidance, discussions, encouragement, and making NSF grant SES-0720753 available for this experiment. I am also grateful to Louis Putterman for continuous advice, discussions and constant support, and to Brian Knight for insightful suggestions and discussions, and seminar audiences at Brown University, George Mason University, University of Vienna, the 81st Annual Meetings of the Southern Economic Association and 2011 Annual International Meeting of the Economic Science Association for helpful suggestions. I thank Urs Fischbacher for sharing his z-tree file used in Falk et al. (2013) with me. I thank the editor, Maggie Penn, and two anonymous referees for their helpful comments.
\end{abstract}

Electronic supplementary material The online version of this article (doi:10.1007/s00355-016-0967-y) contains supplementary material, which is available to authorized users.

Kenju Kamei

kenju.kamei@gmail.com; kenju.kamei@durham.ac.uk

1 Department of Economics, University of Durham, Durham, UK 


\section{Introduction}

Democratic decision processes, in which rules are collectively selected by voting, are used in most societies and organizations today. Both empirical and experimental research suggests that the process by which a policy is implemented may change its outcome by affecting people's level of cooperation on the relevant voted issue through various channels. There are three effects, among others, that democratic processes are known to have: the effects of a selection bias through the endogenous processes (i.e., selection effects), the effects of signals sent through the voting processes, and the democracy premium, which is an effect directly influencing people's behavior (i.e, the residual that cannot be explained by the selection or signaling effects). The literature suggests that the third residual effect may be non-negligible (e.g., Bardhan 2000; Dal Bó et al. 2010; Frey 1997; Sutter et al. 2010, and Tyran and Feld 2006). ${ }^{1}$ Especially, Dal Bó et al. (2010) and Tyran and Feld (2006) find that the democracy premium may be substantial when a policy that can resolve or mitigate a problem is successfully implemented democratically.

Another possible effect that democratic policy selections may have, related to the democracy premium, is changing people's behavior outside the democratic environment. There is large literature on spill-over or transfer of institutional effects on people's behavior from perspectives of other behavioral theories. First, according to the behavioral game theory, there is the so-called behavioral spill-over phenomenon. This refers to the situation where subjects' decisions in an environment can be influenced by their own other decisions made in different environments (e.g., Bednar et al. 2012; Cason et al. 2012).

Second, other studies have demonstrated that the negative effect of the use of monetary incentives in a task-motivation crowding-out-can be transferred to areas indirectly related to the incentivized task such as tasks without it (e.g., Frey 1993; Frey and Benz 2001; Osterloh and Frey 2000; Frey and Jegen 2001). ${ }^{2}$

An indirect institutional effect in the context of democratic decision-making would be one that changes the voters' behavior as a policy intends to even when the policy is undemocratically imposed, if they have experienced a successful democratic implementation of a policy in one area. This is a transfer of motivation crowding-in. For example, imagine a situation where students collectively imposed a No Smoking Policy, an ordinance whose violation is not punishable, into your school by voting. In this example, the students might be more likely to comply with the No Smoking Policy, compared with when the university exogenously imposed it without reflecting their votes or voices; but not only that, they might also become more likely to comply with the No Smoking Policy in public libraries where the rule was autocratically implemented if intrinsic motivations are crowded in among the students.

Apart from these behavioral or institutional theories, income inequality-averse models, such as the prominent Fehr and Schmidt (1999), also predict such positive spill-over effects. Suppose that an inequality-averse person sees that her group

\footnotetext{
1 See Dal Bó (2010) for a summary of experimental evidence.

2 Also see Gneezy and Rustichini (2000).
} 
collectively imposed a policy by voting. Suppose also that she expects that her group members are more likely to respond to the incentive change and behave more cooperatively because it was democratically chosen; and that accordingly mutual cooperation would be more easily attained. In this circumstance, she may raise her compliance, that is, increase her level of cooperation, also in her other group where a policy is autocratically imposed, as her income inequality with the others in the undemocratic environment would increase otherwise. Despite its possibility, such a spill-over effect on the voters' behavior has not received attention in experimental research.

We conduct a laboratory experiment in order to explore a possibility of a spillover effect on the voters' behavior triggered by democratic decision-making. The specific question asked in this paper is: Does succeeding in democratically imposing a non-deterrent sanction policy in a cooperation dilemma raise the voters' level of cooperation even with an undemocratically imposed policy?

Our experiment is based on the framework of a standard linear public goods game. The key design feature is that each subject belongs to two groups with distinct partners and simultaneously plays two public goods games. Each subject is given a fixed endowment for each group and makes an allocation decision between the private account and the public account in that group. Experimental parameters are set so that contributing zero points to the public account in each group is privately optimal, but full contribution is socially optimal. In this environment, a non-deterrent sanction policy may be imposed in each of their two groups. The non-deterrent sanction policy just mitigates the incentive to defect in social dilemmas without altering equilibria for selfish players (e.g., Tyran and Feld 2006). Thus, the mutual full free-riding remains the unique equilibrium in the game even after the policy has been implemented. The setup that the two games are simultaneously played is selected as our focus is not on how people's experiences in cooperation dilemmas under the democracy regime influence their future contribution behavior under undemocratic regimes, but on the presence of democracy premiums. In other words, excluding reputation effects is desirable. For some subjects, a non-deterrent sanction policy is selected democratically in one group, and it is undemocratically imposed by the computer in their other group. We treat these subjects as treatment subjects. For other subjects, the policy is undemocratically imposed by the computer in both of their two assigned groups. We treat these subjects as control subjects. In this paper, we call a group in which the implementation decision is democratically made the "democratic group", irrespective of whether the policy is imposed or not. Likewise, we call a group in which the decision is undemocratically made the "undemocratic group".

Our experiment indicates that when the non-deterrent sanction policy is democratically imposed in a group, subjects who support the policy contribute to the democratic group significantly more than the subjects with the same preference that have never undergone the democratic change. In addition, the former treatment subjects contribute to their undemocratic groups in which the policy is also imposed significantly more, compared with the latter control subjects. This suggests that the democracy premium may be significantly larger than the literature have suggested by the amount of the spill-over effect. By contrast, we find that on average, neither the direct nor 
spill-over effect of democracy is substantial among the opponents of the non-deterrent penalty.

The rest of the paper is organized as follows: Sect. 2 provides the experimental design. Section 3 reports results. Section 4 concludes.

\section{Experimental design}

The experiment has two periods. In each period, subjects play two public goods games, each of which has a group size of two (Sect. 2.1). ${ }^{3}$ At the onset of the experiment, each subject is randomly assigned to two groups of two individuals. To prevent repeated encounters, regardless of their decisions in Period 1, each subject is randomly assigned to two new groups each with a new different individual in Period 2. In other words, we employ the perfect stranger matching protocol. In the second period, a policy may be imposed either democratically or undemocratically in the public goods game (Sect. 2.2.3).

When we measure the democracy premiums, we control for selection effects. Controlling for selection effects is important because subjects' voting decisions and subsequent actions in a game may be correlated with unobservable factors. We apply the method proposed by Dal Bó et al. (2010) to our experiment in order to control for the selection effects. Specifically, all subjects make voting decisions and after that, the computer stochastically assigns either democratic or undemocratic implementation conditions to their groups (Sects. 2.2.1 and 2.2.2). As discussed in Sect. 1, the effects of the democratic process in the voted agenda are composed of (a) selection effects, (b) signaling effects, and (c) the democracy premium. In this paper, we use the term "direct effect of democracy" to refer to effect (c). We use the term "spill-over effect of democracy" to refer to the effect of a person's experience of the successful democratic imposition of a policy on her level of contribution with an undemocratically imposed policy. This is another possible democracy premium. We refer to these two democracy premiums together as the "effects of democracy". The effects of democracy are measured based on subjects' contribution amounts in Period 2.

After Period 2, all subjects take the cognitive reflection test (CRT), and participate in a beauty contest game. ${ }^{4}$ Subsequently, they answer a questionnaire of demographics such as gender (female or male). The CRT scores, beauty contest game responses and the demographic data are used as control variables in analysis. Every participant privately receives payment immediately after the experiment. A schematic diagram of the experiment is included in Fig. 1.5

\footnotetext{
3 We use the minimum group size to obtain the adequate number of independent observations.

4 The CRT consists of three questions. A subject earns seven points for each correct response to the three questions. See Frederick (2005) for the details. In the beauty contest game, each subject chooses an integer between 0 and 100. The subject with the closest number to two thirds of the average of all numbers in a session earns 120 points. See Nagel (1995).

5 Subjects are asked to answer a few comprehension questions to check their understanding of the experiment before the start of the experiment (see online Appendix A for the instructions).
} 


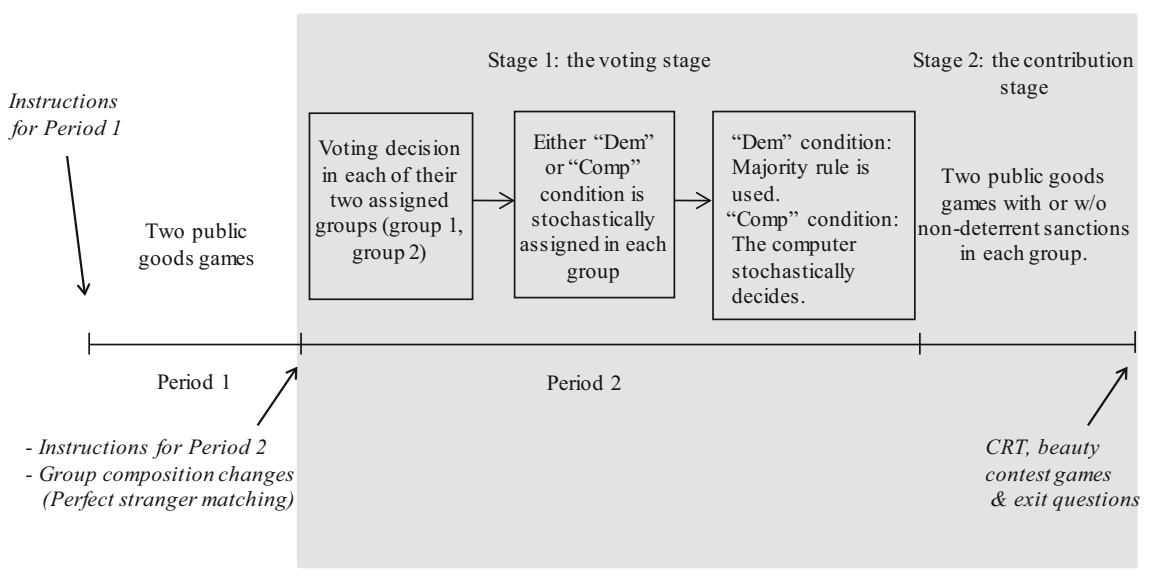

Fig. 1 Schematic diagram of the experiment

\subsection{Period one}

Period 1 plays a role in familiarizing subjects with the voluntary contribution dilemma before their voting decisions. In this period, each subject is given an endowment of 20 points ( 6 points $=\$ 1$ in the experiment) in each of their two assigned groups. Subjects then decide how to allocate their 20 points between a private account and a public account in each group. Only integers between 0 and 20 are allowed for this purpose. The marginal per capita return (MPCR) from the public account equals 0.6 in each group. Thus, subject $i$ 's total payoff in Period $1\left(\pi_{i}^{1}\right)$ is the sum of her payoffs in each group as follows:

$$
\pi_{i}^{1}=\sum_{k=1}^{2}\left[20-C_{i, k}+.6 \cdot\left(C_{i, k}+C_{i^{\prime} \text { s partner }, k}\right)\right]
$$

where $C_{i, k}$ is the contribution amount of subject $i$ in the $k$ th group ( $k=1$ or 2 )

and $C_{i \prime}^{\prime}$ s partner, $k$ is the contribution amount of the subject $i$ 's counterpart in the $k$ th group.

Subjects are informed of their counterparts' allocation amounts to the public account and of their own payoffs at the end of Period 1.

\subsection{Period two}

Our focus in this study is on subjects' contribution behaviors in this period. Period 2 consists of a voting stage followed by a contribution stage.

\subsubsection{The voting stage}

The voting stage proceeds as follows. At the beginning of Period 2, each subject votes on whether to employ a non-deterrent sanction policy in each of their two assigned 
groups separately (see Sect. 2.2.3 for the details of the policy). Each individual votes twice as they belong to two distinct groups. We refer to our subjects as follows: "YesYes voters" are those who supported the policy in both of their two assigned groups, "No-No voters" are those who voted against it in both of their two assigned groups, and "Yes-No voters" are those who voted in favor of the policy in one group and against it in the other.

Once every subject votes, the computer stochastically assigns a democratic condition to one of their two assigned groups. The fraction of subjects to which the democratic condition is assigned is two-thirds. ${ }^{6}$ For these two-thirds of the subjects, irrespective of their votes, the computer stochastically imposes the non-deterrent policy in the other of their two groups. As for the remaining one-third of the subjects, the computer stochastically imposes the policy without reflecting their votes in both of their two assigned groups.

The implementation procedure is as follows: if the democratic condition is given in a group, the computer counts subjects' votes and the majority determines whether to impose the policy in that group. When one person votes for the policy but the other votes against it, the computer stochastically breaks the tie. If the undemocratic condition is assigned to a group, the computer does not consider their votes and just stochastically decides whether to impose the policy (subjects are informed that in this case their votes will not be considered and it is subject to the computer's stochastic choice). We set the probability with which the policy is imposed as follows: under the undemocratic condition, or when the vote share is $50 \%$ under the democratic condition, the computer will implement the sanction policy with a probability of $90 \%{ }^{7}$

We use the following notation: "Dem" (abbreviated from Democratic DecisionMaking) indicates that a majority rule determined whether to impose the policy. "Comp" (abbreviated from Computer) means that the computer stochastically decided it without considering subjects' votes. "Imp" means that the policy was imposed. In this paper, we focus on the following two implementation outcomes: "Dem Imp, Comp Imp" (treatment condition) and "Comp Imp, Comp Imp" (control condition). ${ }^{8}$ Here, "Dem Imp, Comp Imp" reads that for a subject, the non-deterrent policy was imposed in one group reflecting her vote, whereas it was also imposed in her other group as a result of the computer's stochastic choice. "Comp Imp, Comp Imp" reads that the policy was imposed in each of her two assigned groups as a result of the computer's stochastic choice without reflecting her votes (Fig. 2).

\footnotetext{
6 In the experiment, three groups (three subjects in total) are linked with each other, forming a triad. The democratic condition is randomly assigned to one group in each triad (the undemocratic condition is randomly assigned to two groups in each triad).

7 This probability was chosen as the aim of our study is to compare people's compliance with the policy between the two implementation processes. This kind of adjustment in probability was also employed in other studies for their research purposes (e.g., Dal Bó et al. 2010).

8 We note that there are seven pairs of possible implementation outcomes for each subject as they belong to two distinct groups. Referring to the situation where the policy was not imposed as "Not," the other five possible implementation outcomes are "Dem Imp, Comp Not," "Dem Not, Comp Imp," "Dem Not, Comp Not," "Comp Imp, Comp Not," and "Comp Not, Comp Not." Data on these five implementation outcomes is a by-product and is not used for this study.
} 
Treatment Subjects

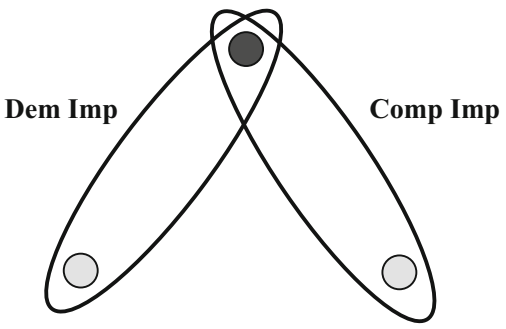

Control Subjects

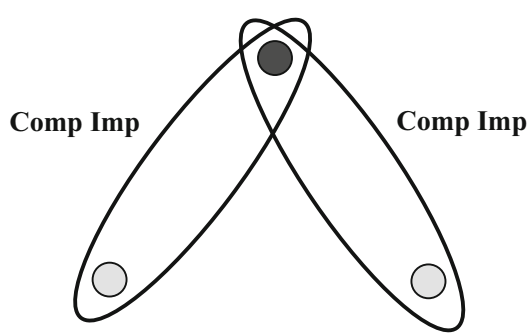

Fig. 2 Treatment subjects and control subjects. Each subject belongs to two distinct groups. Gray circles (•) indicate two distinct counterparts of treatment and control subjects

\subsubsection{Information feedback after the voting stage}

Under the democratic condition, each subject obtains partial information about the vote of her counterpart as their votes determine the imposition of the sanction policy. For instance, suppose that a subject voted against the policy, but the policy was democratically imposed in that group. In this case, she would become aware that her counterpart voted in favor of the policy. If we assume that a subject may develop beliefs about her partner's future cooperation based on the partial information, the difference in the quantity of information between "Dem Imp, Comp Imp" and "Comp Imp, Comp Imp" may become a problem as her contribution behavior may be affected by such beliefs. For this reason, we make this partial information available also to subjects in the undemocratic condition following Dal Bó et al. (2010) to mitigate signaling effects.

The procedure is as follows: all subjects, regardless of whether they are in democratic or undemocratic groups, are informed of whether "at most one person", or "at least one person" voted for the policy in each of their two assigned groups (we refer to the former as the "information At-Most", and the latter as the "information At-Least" in the paper). When the vote share in a group is $50 \%$, the group members receive the Information At-Least and At-Most each with a probability of $50 \%$. Theoretically, the quantity of the information At-Least received by subjects is only slightly higher in the "Dem Imp" condition than in the "Comp Imp" condition because of the adjustment in probability mentioned in Sect. 2.2.1.9

\footnotetext{
9 As explained, each subject is randomly assigned to groups in Period 2. Thus, theoretically, whether one is in a democratic group or an undemocratic group, the probability with which a Yes-Yes voter is paired with another Yes-Yes voter or a Yes-No voter is the same. Therefore, for a Yes-Yes voter, regardless of the implementation processes, the probability with which the policy is implemented is almost the same: while it is $90 \%$ in an undemocratic group, it is $94.7 \%$ in a democratic group. Here, the latter probability was calculated by using the ex-post probabilities (Appendix Table B.1) based on the distribution of actual votes as follows: $\operatorname{Pr}($ Partner is a Yes-Yes voter $)+[.5+.5 \cdot .9] \cdot \operatorname{Pr}($ Partner is a Yes-No voter $)+.9 \cdot \operatorname{Pr}($ Partner is a No-No voter $)$ $=94.7 \%$. As a result, the expected probabilities with which Yes-Yes voters will receive the information At-Least are $75.0 \%$ in their democratic groups under the treatment condition, and $73.7 \%$ in their undemocratic groups under the treatment condition or under the control condition. These two are almost the same to each other. Here, these two probabilities were calculated as follows:

(a) Pr(info. At-Least in the democratic group|"Dem Imp, Comp Imp" and a decision-maker is a Yes-Yes voter)
} 
We note that as an anonymous referee pointed out, having this information feedback alone is not enough to fully control for signaling effects in measuring the 'direct' effect of democracy even though the quantity of the information At-Least is balanced between the "Dem Imp" and "Comp Imp" conditions. This is because subjects are not informed of the exact probability that the sanction policy is imposed in case of a tie in democratic groups. We discuss the details of the signaling effect and explore the relative strength of it compared with the direct effect of democracy in Sect. 4. By contrast, we are able to identify the 'spill-over' effect of democracy while fully controlling for the size of signaling effects if the quantity of the information At-Least is balanced. This is because we measure the difference in contribution amount between the treatment subjects (who belong to "Dem Imp, Comp Imp") and the control subjects (who belong to "Comp Imp, Comp Imp") in the same type of group—-Comp Imp" group. Before conducting data analyses, we test whether the quantity of the information At-Least is statistically balanced (a) between the treatment subjects in "Dem Imp" groups and the control subjects in "Comp Imp" groups; and (b) between the treatment subjects in "Comp Imp" groups and the control subjects in "Comp Imp" groups. ${ }^{10}$

\subsubsection{The contribution stage}

As discussed, a non-deterrent sanction policy may be imposed in each group in Period 2. The MPCR equals 0.6 in this period as well. When the policy is put in place, each point that a subject allocates to her private account results in a fine of 0.3 points. In other words, when subject $i$ contributes $C_{i, k}$ to her public account in her $k$ th group $(k \in\{1,2\})$, she obtains the following payoff $\left(\pi_{i, k}^{2}\right)$ :

$$
\pi_{i, k}^{2}=\left(20-C_{i, k}\right) \cdot\left(1-0.3 \cdot I_{\{\text {implement }, k\}}\right)+0.6 \cdot\left(C_{i, k}+C_{i^{\prime} s \text { partner }, k}\right),
$$

where $I_{\{\text {implement }, k\}}=1$ if the policy is implemented in the $k$ th group; $=0$ otherwise. $C_{i}{ }^{\prime}$ spartner, $k$ is the contribution amount of subject $i$ 's interaction counterpart in her $k$ th group. The total payoff of subject $i$ in this period are the sum of her payoffs in her two assigned groups $\left(\pi_{i}^{2}=\sum_{k=1}^{2} \pi_{i, k}^{2}\right)$.

We note that treatment subjects simultaneously belong to a democratic group and an undemocratic group. These two groups are different from each other even if the same policy is implemented in each group, because the implementation process is different in each group. In this contribution stage, subjects have reminders of what determined the scheme in each of their two assigned groups and how the vote went in

Footnote 9 continued

$=\frac{\operatorname{Pr} \text { ("Dem Imp, Comp Imp" and the Yes-Yes voter receives the info. At-Least in her democratic group) }}{}$ Pr ("Dem Imp, Comp Imp" and a decision-maker is a Yes-Yes voter) $=(.9 \cdot\{.423+(.5+.5 \cdot .9 \cdot .5) \cdot .10+.9 \cdot .5 \cdot .477\}) /\{.9 \cdot .947\} \approx 75.0 \%$.

(b) $\operatorname{Pr}$ (a Yes-Yes voter receives info. At-Least in her "Comp Imp" group under "Dem Imp, Comp Imp" l"Dem Imp, Comp Imp" and a decision-maker is a Yes-Yes voter) = Pr(a Yes-Yes voter receives info. At-Least in her "Comp Imp" group under "Comp Imp, Comp Imp" |"Comp Imp, Comp Imp" and a decision-maker is a Yes-Yes voter $)=\operatorname{Pr}($ a Yes-Yes voter receives Info. At-Least in the "Comp Imp" group) $=.423+.5 \cdot .10+.5 \cdot .5 \cdot .10+.5 \cdot .47 .7 \approx 73.7 \%$.

10 The quantity of the information At-Least was in fact statistically balanced between the two kinds of groups in the experiment (see Sect. 3). This was expected as explained in footnote 9. 
each group on their computer screens to avoid confusion (see Appendix Fig. B.1 for examples of reminders on the screen).

\subsubsection{Some discussions concerning predictions}

Regardless of whether the sanction policy is imposed in Period 2, contributing nothing to the public account is the strictly dominant strategy for a subject under the assumption that the subject is selfish. This is because the policy is sufficiently weak: $1.0-0.3>0.6$ [see Eq. (2)]. As a result, allocating all points to her private account is the unique Nash equilibrium (NE) for material payoff maximizers, although contributing the full endowment to the public account is the social optimum. Therefore, the sanction policy, if imposed, will cause her to pay a maximum fine of 6 points $(=0.3 \times 20)$. Each subject's vote is pivotal in each group as the group size is two. Thus, the standard theory predicts that each subject will vote against the policy in both of her two assigned groups (Subgame Perfect Nash Equilibrium). Appendix Fig. B.2 includes the game tree of the experiment.

Subjects may, however, vote for the policy and then voluntarily contribute to that group when the policy is selected. This is because, first of all, the sanction policy reduces the temptation to defect. If some subjects are not self-interested and instead have other-regarding preferences, such as reciprocity (e.g., Rabin 1993) and income inequality aversion (e.g., Fehr and Schmidt 1999), mutual cooperation would become more easily achieved as an equilibrium with help of the non-deterrent sanction policy. Second, voting in favor of the sanction policy could be considered a credible way of signaling an intention to cooperate, since each subject knows that their votes will be informed to their partners by the information feedback rule.

Subjects' compliance or contribution decisions with the sanction policy might differ by how a policy is imposed as in other related studies. If experiencing a successful democratic imposition of the policy affects subjects' beliefs about their partners' future action choices or enhance their social preferences, subjects in the democratic group may contribute more to that group, compared with the control subjects. Further, subjects' responses to the successful endogenous imposition may differ by voter type. For instance, suppose that subjects have reciprocal preferences. Then, Yes-Yes voters may exhibit positive reciprocity for the outcome that the policy was imposed reflecting their votes. Such reciprocity is absent in the undemocratic condition as the computer stochastically imposes a policy in that condition. If reciprocity plays a role, we may find positive direct effects of democracy for Yes-Yes voters.

As discussed in Sect. 1, moreover, the spill-over or transfer of institutional effects, or income inequality-averse preference models can predict the presence of positive spill-over effects of democracy if the direct effect of democracy is present.

\section{Results}

A total of three hundred undergraduate students at Brown University participated in the experiment in April and May, 2010. 15 sessions were conducted in a computer 
laboratory at Brown University. ${ }^{11}$ No subject participated in more than one session. The sessions lasted around one hour on average. Subjects were privately paid at the end of the experiment. The average earnings were $\$ 21.38$ (including a $\$ 5$ participation fee) with a standard deviation of $\$ 5.04$. The instructions for the experiment were neutrally framed. The instructions were read aloud by the experimenter to subjects. The experiment was programmed in z-tree (Fischbacher 2007). Communication between subjects was not permitted during sessions.

The average contribution in Period 1 was 5.96 points, with a standard deviation of 6.06 points. Contributing $30 \%$ of the endowment in a one-shot experiment is not unusual. This is near the lower end of the range that is predicted from previous experiments in the literature, given the lower efficiency of the group optimum (see Ledyard 1995 and Zelmer 2003).

Out of the 300 subjects, around $42 \%$ of them voted for the non-deterrent policy in both of their two assigned groups, $48 \%$ voted against the policy in both of their assigned groups, and only $10 \%$ of them voted differently in their two groups (Appendix Table B.1). Considering this distribution, we focus on measuring the effects of democracy on the Yes-Yes and No-No voters only. As a result of the subjects' votes and the computer's stochastic decisions, 120 subjects were faced with the treatment condition ("Dem Imp, Comp Imp") and 76 were faced with the control condition ("Comp Imp, Comp Imp") in Period 2. Of the 120 treatment subjects, 67 were Yes-Yes voters and 37 were No-No voters. Of the 76 control subjects, 31 were Yes-Yes voters and 37 were No-No voters (Appendix Table B.2).

\subsection{The direct and spill-over effects of democracy}

In the experiment, all subjects received either the information At-Least or the information At-Most, regardless of whether they belonged to a democratic group or an undemocratic group. The fractions of subjects that received the information At-Least were statistically balanced between the democratic and undemocratic conditions for each voter type. ${ }^{12}$ Thus, we can measure the direct effect of democracy while controlling for signaling effects to a large degree. The spill-over effect of democracy can be measured with signaling effects fully controlling for. We identify the two kinds of

\footnotetext{
11 Participants were recruited from the general student population there, using the Brown University Social Science Experiment Lab (BUSSEL) on-line recruitment system. 46 out of the 300 subjects listed economics as one of their concentrations. This fraction was similar to the proportion of economics majors in the university's undergraduate population. Other participants came from fields ranging from the humanities to the sciences. The number of participants per session was 21,18 or 15 . All subjects were first-time participants in public goods game experiments.

12 In the treatment condition ("Dem Imp, Comp Imp"), out of the 67 Yes-Yes voters, $77.6 \%$ of them received the information At-Least in their democratic groups and $71.6 \%$ received it in their undemocratic groups. By contrast, in the control condition ("Comp Imp, Comp Imp"), out of the 37 Yes-Yes voters, they received it in $66.1 \%$ of the cases. The ratios, 77.6, 71.6 and 66.1\% are not statistically significant according to two-sided, two-sample tests of proportions. Similar holds also for No-No voters. In the treatment condition, out of the 37 No-No voters, $37.8 \%$ of them received the information At-Least in their democratic groups and $21.6 \%$ received it in their undemocratic groups. By contrast, in the control condition, No-No voters received it in $28.4 \%$ of the cases. The ratios, 37.8, 21.6, and $28.4 \%$ are not statistically different. See Appendix Table B.4 and footnote 9 also.
} 
democracy premiums for each voter type. ${ }^{13}$ The direct effect of democracy is identified by comparing (a) the contribution amounts in the democratic groups in the treatment condition ("Dem Imp, Comp Imp") and (b) the contribution amounts in the undemocratic groups in the control condition ("Comp Imp, Comp Imp"). The spill-over effect of democracy is identified by comparing (c) the contribution amounts in the undemocratic groups in the treatment condition and (b) mentioned above (See Fig. 2 also). ${ }^{14}$

\subsubsection{The effects of democracy on yes-yes voters}

The contribution amounts by the supporters of the non-deterrent sanction substantially differ by their experience of the democratic process. Yes-Yes voters on average contributed 16.55 points to their democratic groups and 15.73 points to their undemocratic groups in the treatment condition (Table 1). This is in sharp contrast with Yes-Yes voters in the control condition: they contributed much smaller amounts, 12.05 points on average, to their undemocratic groups. Thus, the direct effect of democracy is 4.5 points $(=16.55-12.05)$, which is $22.5 \%$ of the endowment. The spill-over effect of democracy is 3.7 points $(=15.73-12.05)$, which is $18.4 \%$ of the endowment. A regression analysis, shown in column (1) and (5) of Tables 2 and 3, finds that both the direct and spill-over effects of democracy are significant at the 1 and $5 \%$ level, respectively. ${ }^{15}$ The sizes of the direct effect and of the spill-over effect decrease to 3.35 points and 3.05 points, which are reductions of 25.5 and $17.7 \%$ respectively, if control variables are added, as shown in columns (2) and (6), but these are significant at the $10 \%$ level. The size of the direct effect of democracy is greater than that of the spill-over effect of democracy. ${ }^{16}$

The effects of democracy can alternatively be measured by the use of the median. As shown in columns (3), (4), (7) and (8), both the direct and spill-over effects are significant at the 1 or $5 \%$ level, regardless of whether control variables are included or not.

\footnotetext{
${ }^{13}$ In the working paper version of this paper, we also explored how the effects of democracy differ by gender or by cooperative disposition, finding that the effects of democracy we find for those who support the policy are driven by the male subjects. We also find that the size of the effects of democracy differ by subject's cooperative disposition. See Kamei (2014) for the details.

14 We use regression methods to identify the two democracy premiums as it enables us to include control variables for robustness check. We acknowledge that non-parametric tests are equally important; we report Mann-Whitney test results in footnotes 15 and 20. As explained later, our findings are robust.

15 The average contribution of 16.55 points in the treatment condition and 12.05 points in the control condition are significantly different according to an individual-level Mann-Whitney test ( $p$ value $=.0051$, two-tailed), so are 15.73 points and 12.05 points ( $p$ value $=.018$, two-tailed). The regression models in Tables 2 and 3 (and Tables 4,5) were estimated separately for each of the direct and spill-over effects of democracy. This is because including contribution amounts both in their democratic and undemocratic groups along with two dummy variables in a single equation to measure the direct and spill-over effects requires clustering standard errors by individual ID. However, the finite sample bias of clustering is known to be greater when the size of clusters is small.

16 They are significantly different at the $10 \%$ level if we use one-tailed Wilcoxon signed ranks test ( $p$ value $=0.080$ ). This is suggestive evidence of the treatment subjects discriminating their contribution behaviors between the two groups to some degree.
} 


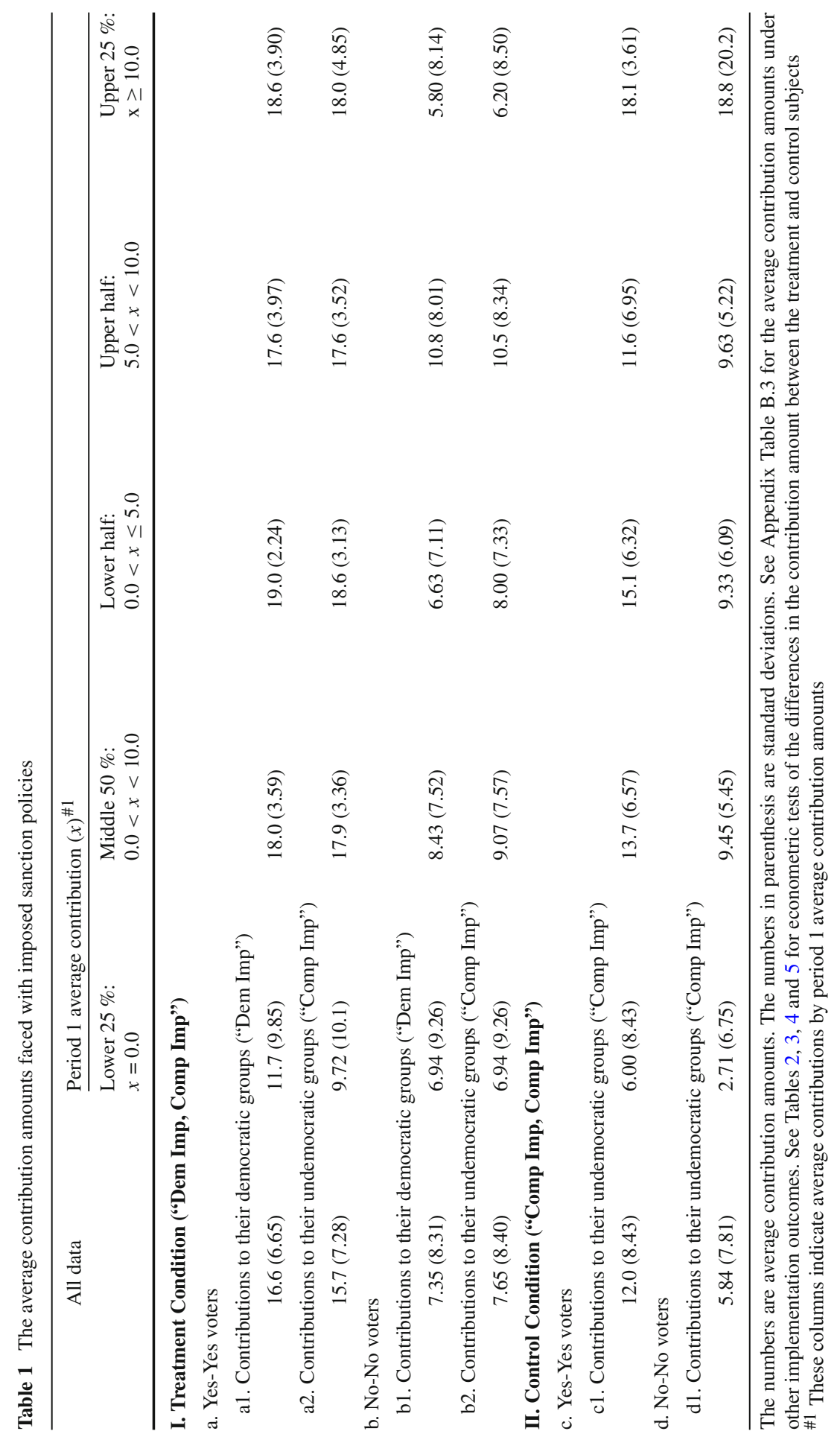




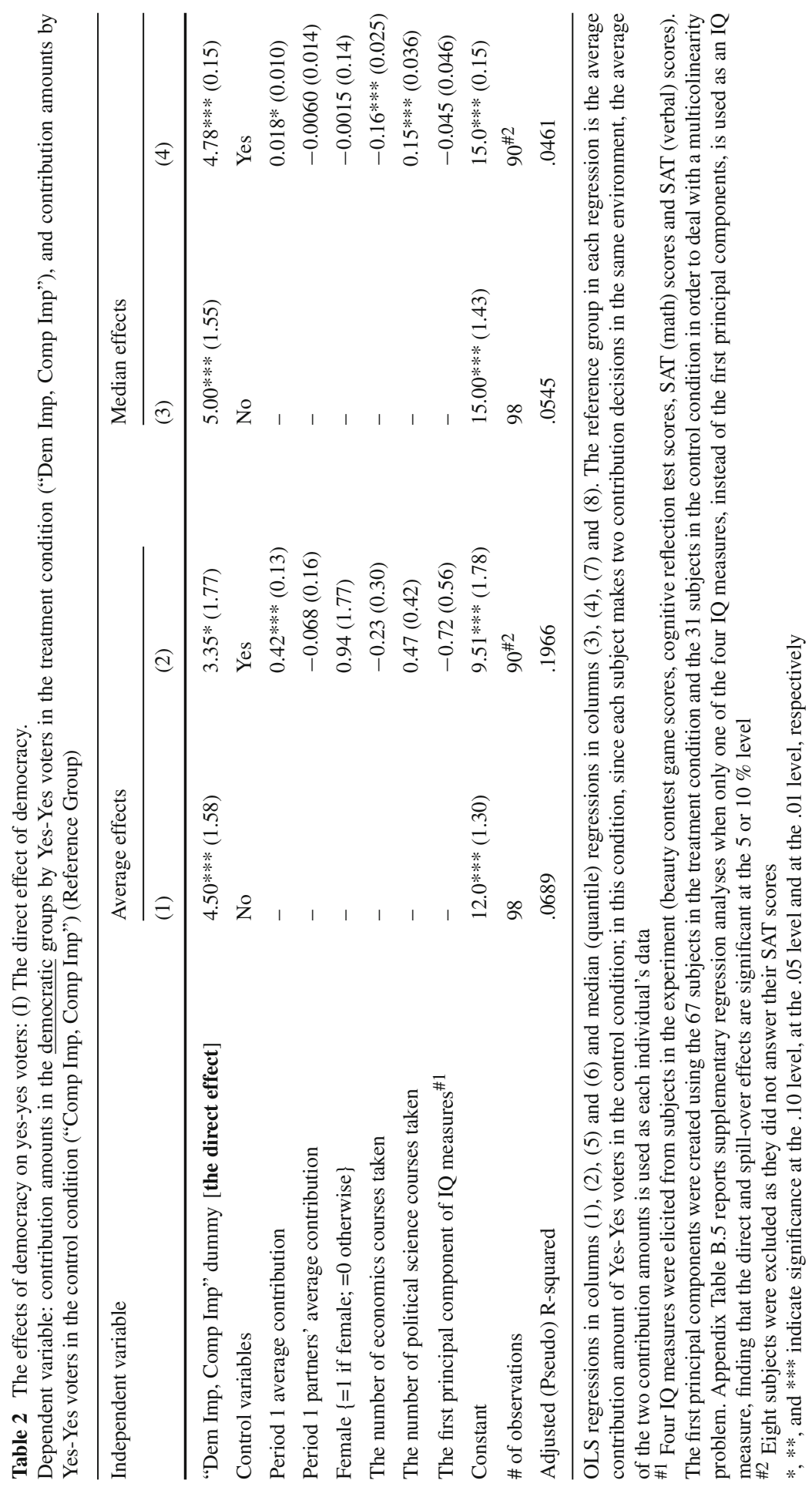




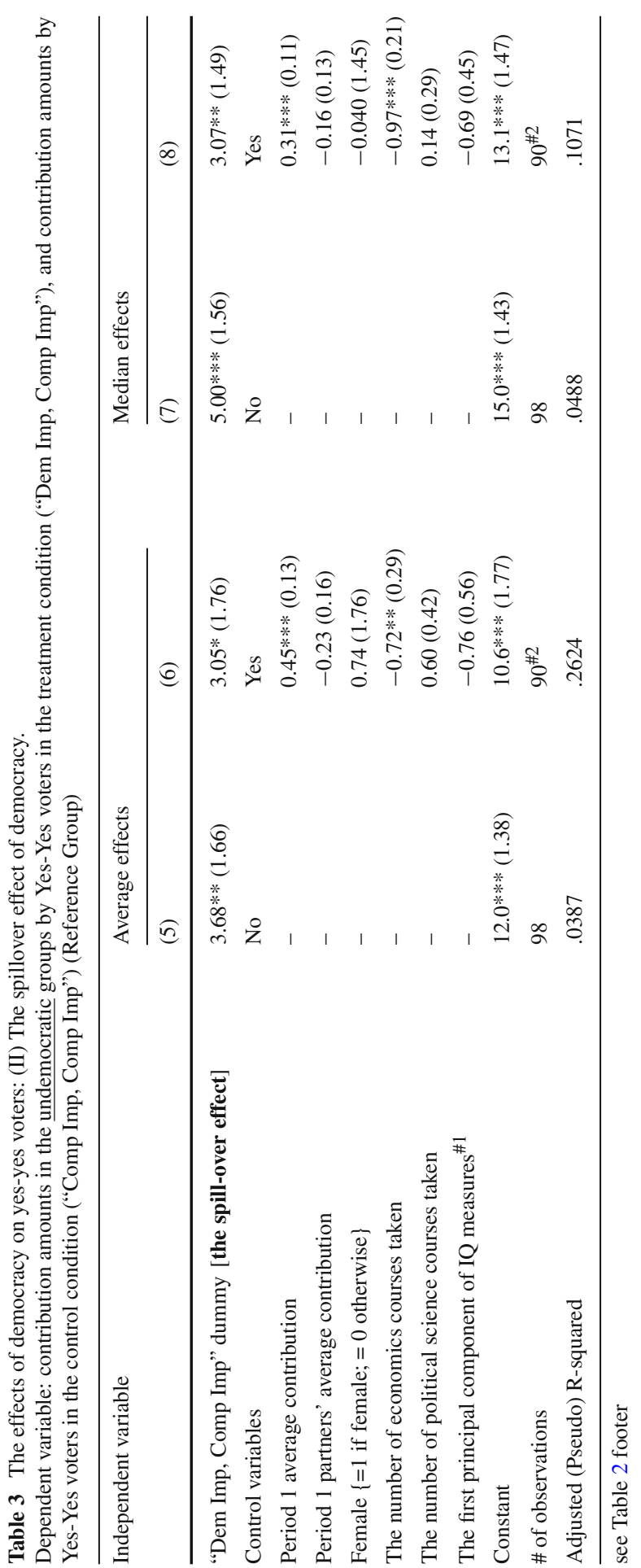


Our result that Yes-Yes voters raise their level of cooperation significantly responding to a democratically imposed non-deterrent policy, compared with Yes-Yes voters under the control, is consistent with recent work by Dal Bó et al. (2010) and Tyran and Feld (2006). ${ }^{17}$ The results of ours and these previous studies resonate with the idea that the supporters of a policy exhibit a strong motivation crowding-in effect or strong positive reciprocity to the collective outcome that a policy is democratically imposed reflecting their approving votes. The result that the supporters of the sanction in the treatment condition raise their compliance even with an undemocratically imposed sanction rule implies that the impact may spill over to their behavior in a second domain. ${ }^{18}$

\section{Result 1: Yes-Yes voters exhibit the direct and spill-over effects of democracy.}

The fractions of subjects that received the information At-Least were statistically balanced between democratic groups and undemocratic groups for each voter type. However, as an anonymous referee pointed out, I acknowledge that the equal distributions of information do not assure that subjects have the same posterior beliefs between the "Dem Imp" condition and "Comp Imp" condition. More specifically, Yes-Yes voters' posterior beliefs on their partner's voter type when they received the information At-Least depend on whether they were in the "Dem Imp" condition or "Comp Imp" condition. Thus, the result on the direct effect of democracy in Result 1 may not be clean. This happens due to the fact that the non-deterrent sanction policy was imposed with a probability of $90 \%$ in case of a tie under the "Dem Imp" condition, but subjects were not informed of the exact probability. In the remaining of Sect. 3.1.1, we explain why this design piece can lead to a difference in subjects' posterior belief. We then show that our results on the direct effect in Result 1 are not attributable to signaling effects. We note that Yes-Yes voters who received the information At-Most are fully comparable between the "Dem Imp" and "Comp Imp" conditions because Yes-Yes voters' posterior beliefs that opponents are also Yes-Yes voters are 0 with the information At-Most in both of the conditions.

On the one hand, the posterior belief that a Yes-Yes subject forms in the "Dem Imp" group depends on her prior belief that her partner is a Yes-Yes voter (which we denote as $p^{\text {prior }}$ ), which information she receives (At-Most or At-Least), and the probability that the computer imposes the non-deterrent sanction in case of a tie. We use $\gamma \in[0,1]$ to express the probability that the computer imposes it in case of a tie. Then, according to the Bayes Rule, the Yes-Yes voter believes that her opponent

17 Dal Bó et al. (2010) shows that when a prisoner's dilemma game is democratically changed to a coordination game where the mutual cooperation is also an equilibrium, the supporters of the modification cooperate significantly more. Tyran and Feld (2006) show the possibility of a significant democratic effect in the case of a lump-sum non-deterrent fine in a social dilemma.

18 A reader may pose the possibility that some subjects were confused about what determined the scheme in each of their two assigned groups in the contribution stage. However, this is very unlikely since the Footnote 18 continued

voting stage proceeded separately in each of their two assigned groups. In addition, in the contribution stage subjects received reminders about implementation outcomes, including what determined the scheme in each of their two assigned groups (the computer or their votes), on their computer screens (see Sect. 2.2.3 and Appendix Fig. B.1). 
is also a Yes-Yes voter with a probability of $p_{\text {Dem Imp }}^{\text {posterior }}=\frac{p^{\text {prior }}}{p^{\text {prior }}+0.5 \cdot \gamma^{b} \cdot\left(1-p^{\text {prior }}\right)}$ if she receives the information At-Least. Here, $\gamma^{b}$ is her belief on $\gamma$. On the other hand, the posterior belief that a Yes-Yes voter forms in the "Comp Imp" group depends on his prior belief and which information he receives (At-Most or At-Least) only. The Yes-Yes voter's posterior belief that his opponent is also a Yes-Yes voter is: $p_{\text {Comp Imp }}^{\text {posterior }}=\frac{p^{\text {prior }}}{p^{\text {prior }}+0.5 \cdot\left(1-p^{\text {prior }}\right)}$ if he receives the information At-Least. We see that unless $\gamma^{b}=1$, posterior $>p_{\text {Dem Imp Imp }}^{\text {posterior }}$. In the experiment, $\gamma=.9$, which is close to 1.0; however, the value of $\gamma$ is not known to subjects. Therefore, subjects' beliefs on $\gamma$ are not equal to .9. We can assume that subjects believe, for example, that the sanction policy would be imposed with a probability of $50 \%$ (i.e., $\gamma=.5<.9$ ), which makes $p_{\text {Dem Imp }}^{\text {posterior }}$ larger. In other words, signaling effects can be theoretically stronger under the "Dem Imp" groups than under the "Comp Imp" groups, and thus contribution amounts made in the "Dem Imp" groups may be overestimated.

In order to formally study how Yes-Yes voters' contribution behaviors are affected by posterior beliefs, we conduct a regression analysis in which the dependent variable is subject $i$ 's contribution amount in her democratic group in the treatment condition ("Dem Imp, Comp Imp"). The independent variables include the Information At-Least dummy variable (which equals 1 if $i$ receives the information At-Least; 0 otherwise). With this regression analysis, we can gauge the effect of having the information AtLeast, instead of the information At-Most, on the treatment subjects' action choices in the "Dem Imp" groups. As shown in Appendix Table B.6, we find that the information At-Least dummy fails to obtain a significant coefficient. This means that signaling effects are not the main forces that drive Result 1 concerning the direct effect of democracy. We note that it is well-known that signaling effects are usually important channels that boost cooperation (e.g., Tyran and Feld 2006). A likely reason that the information At-Least dummy does not obtain a significant coefficient is that Yes-Yes voters contributed very large amounts even when they received the Information 'At-Most' (with which $p_{\text {Dem Imp }}^{\text {posterior }}=0$ ) in our context (See Table B.4). This suggests that the direct effect of democracy was indeed strong and there was no room for a further increase in contribution by having additional positive signaling effects in the experiment.

We lastly note that the 'spill-over' effect of democracy in Result 1 was identified while signaling effects were fully controlled for since the quantity of the information At-Last in the "Comp Imp" groups was sufficiently balanced between Yes-Yes voters in the treatment and control conditions. The posterior beliefs of the treatment and control subjects are both given by $p_{\text {Comp Imp }}^{\text {posterior }}=\frac{p^{\text {prior }}}{p^{\text {prior }}+0.5 \cdot\left(1-p^{\text {prior }}\right)}$ mentioned above. ${ }^{19}$ It should also be noted that for each Yes-Yes voter in the treatment condition, a partner in the "Comp Imp" group was different from her other partner in the "Dem Imp" group.

\footnotetext{
19 We ran regressions where the dependent variable is Yes-Yes voters' contribution amounts under the "Comp Imp" group in the treatment condition ("Dem Imp, Comp Imp") condition nevertheless. As is similar to the regression result for the direct effect part, we find that Yes-Yes voters' action choices were little affected by which information (the information At-Least or At-Most) they received. This results from the finding that the democracy spill-over is indeed strong and the treatment subjects contributed very large amounts in the "Comp Imp" groups without any help of signaling effects (i.e., with receiving the information At-Most). See columns (3) and (4) of Appendix Table B.6.
} 


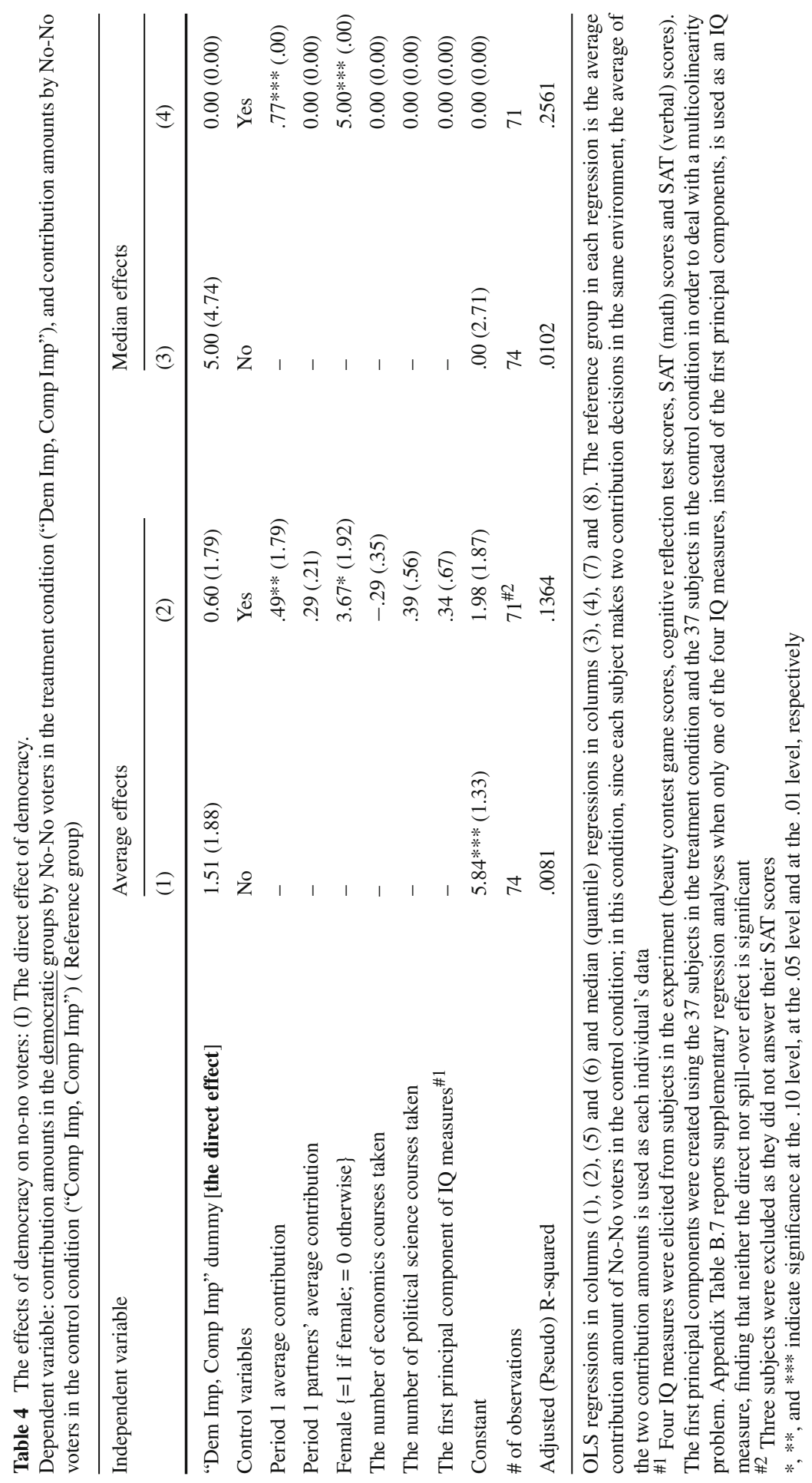




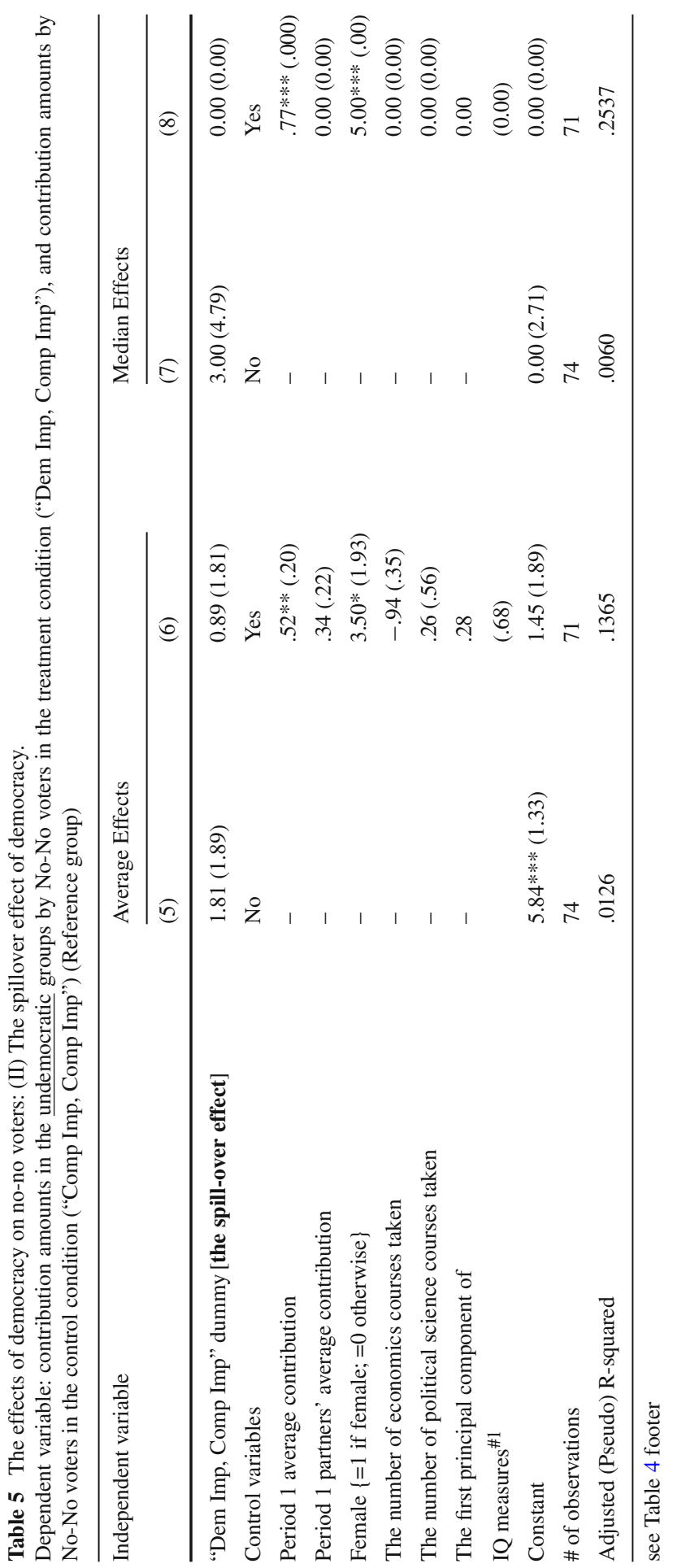




\subsubsection{The effects of democracy on no-no voters}

The impacts of democracy on No-No voters are different from those on Yes-Yes voters. On the one hand, the opponents of the non-deterrent sanction policy in the treatment condition on average contributed 7.35 points in their democratic groups and 7.65 points in their undemocratic groups. On the other hand, No-No voters in the control condition on average contributed 5.84 points in their undemocratic groups (Table 1). The direct effect of democracy, 1.51 points on average $(=7.35-5.84)$, and the spill-over effect of democracy, 1.81 points on average $(=7.65-5.84)$, are both insignificant (Tables $4,5) .{ }^{20}$ Results are similar when the median contribution is used to gauge the direct or spill-over effect on No-No voters.

The result that the opponents of the policy exhibit neither the direct nor spill-over effect of democracy is similar to the result in Dal Bó et al. (2010).

Result 2: No-No voters do not exhibit either the direct or spill-over effect of democracy.

\section{Conclusion}

This paper provides the first evidence that a successful democratic imposition of a policy may generate not only a direct effect, but also a spill-over effect on behaviors of those who are involved in the democratic policy selection. When the subjects who democratically changed the payoff structure in one group are placed in other groups in which the change was imposed undemocratically, they contributed significantly more than those who have never undergone the democratic change. Moreover, our data finds that these positive democracy premiums were limited for those assenting to the policy; the effects were not seen in those who voted against it.

Our findings have broad implications for economic policy, organization economics, and political economy. When a policy is democratically implemented reflecting people's votes, the extra effects of a democratically implemented policy (i.e., democracy premiums) may not be limited to the relevant social dilemma, but may also emerge in another social dilemma through resilient behavioral responses of those assenting to the policy. Such a spill-over effect may be substantial even if the policy is sufficiently weak as in the non-deterrent policy in this study.

As a final remark, we note that the result on the spill-over effect has a methodological implication in identifying the effects of a policy or democracy premiums. We have two potential methods to measure such effects, whether experiments or empirical studies. The first method is to let each subject play games both in the treatment condition and the control condition, and then to compare their behaviors between the two conditions. The second method is, by contrast, to divide subjects into two kinds of groups: treatment groups and control groups, let them play the games only in one assigned condition and compare behaviors between the two kinds of groups. Which method should we use? Our results indicate that the first method may not be accurate, due to the spill-over effect

\footnotetext{
20 The average contribution of 7.35 points in the treatment condition and 5.84 points in the control condition are not significantly different according to an individual-level Mann-Whitney test ( $p$ value $=.45$, two-tailed), nor are that of 7.65 points and 5.84 points ( $p$ value $=.41$, two-tailed).
} 
of democracy, and that employing the second method may be a more conservative way to measure the effects.

Open Access This article is distributed under the terms of the Creative Commons Attribution 4.0 International License (http://creativecommons.org/licenses/by/4.0/), which permits unrestricted use, distribution, and reproduction in any medium, provided you give appropriate credit to the original author(s) and the source, provide a link to the Creative Commons license, and indicate if changes were made.

\section{References}

Bardhan P (2000) Irrigation and cooperation: an empirical analysis of 48 irrigation communities in South India. Econ Dev Cult Change 48:847-865

Bednar J, Chen Y, Liu T, Page S (2012) Behavioral spillovers and cognitive load in multiple games: an experimental study. Games Econ Behav 74:12-31

Cason T, Savikhinb A, Sheremeta R (2012) Behavioral spillovers in coordination games. Eur Econ Rev 56:233-245

Dal Bó P (2010) Experimental Evidence on the workings of democratic institutions. In: Galiani S, Sened I (eds) Institutions, property rights, and economic growth: the legacy of Douglass North. Cambridge University Press, Cambridge

Dal Bó P, Foster A, Putterman L (2010) Institutions and behavior: experimental evidence on the effects of democracy. Am Econ Rev 100:2205-2229

Falk A, Fischbacher U, Gächter S (2013) Living in two neighborhoods-social interaction effects in the lab. Econ Inq 51:563-578

Fehr E, Schmidt K (1999) A theory of fairness, competition, and cooperation. Q J Econ 114:817-868

Fischbacher U (2007) z-Tree: Zurich toolbox for ready-made economic experiments. Exp Econ 10:171-178

Frederick S (2005) Cognitive reflection and decision-making. J Econ Perspect 19:25-42

Frey B (1993) Motivation as a limit to pricing. J Econ Psychol 14:635-664

Frey B (1997) A constitution for knaves crowds out civic virtues. Econ J 107:1043-1053

Frey B, Benz M (2001) Motivation transfer effect. mimeo

Frey B, Jegen R (2001) Motivation crowding theory. J Econ Surv 15:589-611

Gneezy U, Rustichini A (2000) A fine is a price. J Legal Stud 29:1-17

Kamei K (2014) Democracy and resilient pro-social behavioral change: an experimental study. http://papers. ssrn.com/sol3/papers.cfm?abstract_id=1756225

Ledyard J (1995) Public goods: a survey of experimental research. In: Kagel JH, Roth AE (eds) Handbook of experimental economics. Princeton University Press, Princeton, pp 111-194

Nagel R (1995) Unraveling in guessing games: an experimental study. Am Econ Rev 85:1313-1326

Osterloh M, Frey B (2000) Knowledge transfer, and organizational forms. Organ Sci 11:538-550

Rabin M (1993) Incorporating fairness into game theory and economics. Am Econ Rev 83:1281-1302

Sutter M, Haigner S, Kocher M (2010) Choosing the carrot or the stick? Endogenous institutional choice in social dilemma situations. Rev Econ Stud 77:1540-1566

Tyran J-R, Feld L (2006) Achieving compliance when legal sanctions are non-deterrent. Scand J Econ 108:135-156

Zelmer J (2003) Linear public goods experiments: a meta-analysis. Exp Econ 6:299-310 